When applying it to the fore limb, it must sometimes be curved outwards and backwards opposite the fetlock joint, to avoid contact with this joint in certain conformations. The jaw at the top prevents this curve getting the wrong way round.

This system will be found far more easy of application and retention than all the splints and bandages ever applied. It is unsuitable for any case suspected of fracture in the lower bones of the limbs.

\title{
CASE OF BOTRYOMYCOSIS IN A HORSE.
}

By John B. WOLSTENhOLME, F.R.C.V.S, Manchester.

Patient, a red roan cart gelding; ten years old. Part affected, the skin and subcutaneous connective-tissue at the lower posterior part of the left thigh.

For four years the horse had worked in the shafts of a four-wheeled heavy vehicle; but at the latter part of 1900 he was put to work in chain trace gears.

The "spreader" or "stretcher" of the traces would ride or be carried on that part of the thigh which is affected; this may have had some part in causing the lesion.

In November I900 a small boil, about the size of a hazel nut, formed over the part, and then burst. From this time onward others formed and gave exit to small quantities of pus, which quickly dried.

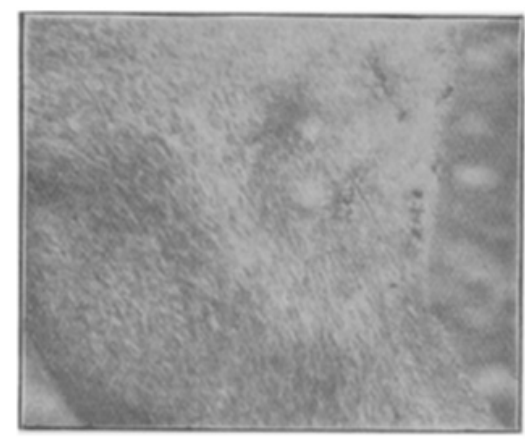

It was I 2 th June IgoI when he came under my notice, at which time there were three or four points of suppuration, several cicatrices, and considerable thickening of the skin and subcutaneous tissue around.

At the end of October, when the accompanying photograph was obtained, the area of disease had spread until it occupied both the inner and outer aspects of the thigh, and extended in a perpendicular direction $I 1 \frac{1}{2}$ inches, and $I 3 \frac{1}{2}$ inches across.

The skin and subcutancous connective-tissue is thickened and studded with eighteen depressions of about five-eighth inch diameter, which represent a corresponding number of abscesses and ulcers, most of which are healed.

When an abscess bursts a pale yellow viscid pus escapes, a portion of which dries on the wound and forms a firm crust. 
Examination of the pus shows the presence of a number of grey opaque points, just visible to the naked eye, which when transferred to a slide and examined under a one-inch objective are seen to be colonies of the botryomyces equi.

They are easily examined in a drop of water or glycerine, but come out beautifully when stained with rubin and orange.

Of half-a-dozen colonies measured, the size varied from $0.2 \mathrm{~mm}$, to $0.45 \mathrm{~mm}$.

\title{
INTRACEREBRAL INJECTION OF ANTITETANIN FOR THE CURE OF TETANUS IN THE HORSEx
}

\author{
By Sidney Vili.ar, F.R.C.V.S., Harrow.
}

CASE I.-On 9th June of the present year a small black male pony was brought to my Infirmary affected with tetanus. The animal was distressed somewhat by its walk of 3 miles, the disease was in its initial stage, and, although the usual symptoms were well marked, it quickly got over the effects of the journey.

The course of the disease in this case was subacute. The pony was put in a loose box, kept perfectly quiet, and had solution of extract of belladonna daily in its drinking water, being mean while well nursed and supplied with suitable food.

It continued to get gradually worse, and, as on the $7^{\text {th }}$ June trismus was becoming very marked, I determined to resort to the intracerebral injection of pure antitetanin ${ }^{1}$, the pony being a suitable subject for this operation on account of its small size and gentle disposition.

On the morning of I 8 th June, having well washed the skin of the forehead with perchloride of mercury soap, shaved it as closely as the movements of the pony would permit, and having injected subcutaneously 3 grains of cocaine in solution, I incised and dissected an angular flap of skin about one-and-a-half inches in length, and cut through the temporal muscles and for a small space detached them from the bone beneath, thus exposing a small portion of the right parietal bone at a distance of one inch from the parietal ridge, on a line with the anterior margin of the root of the ear. With an archimedian drill, bought at an ironmongers for Is. $6 \mathrm{~d}$., a small circular hole was made through the bone, the length of the drill being previously limited to rather more than an inch by threading a cork on it. Through the hole thus made the needle of an ordinary hypodermic syringe was pushed right into the substance of the cerebral hemisphere, and about $3 \mathrm{cc}$. of pure antitetanin was injected.

The needle having been withdrawn, the wound was dressed with iodoform and cotton wool.

Throughout the operation the pony gave no indication of experiencing inconvenience; it was returned to the box and not seen by me again for twenty-four hours, at the end of which period there was a very marked abatement of the tetanic symptoms. The groom said it had emptied its manger during the night, and it was feeding fairly well when I saw it. During the next ten days the tetanic symptoms

1 See article by MM. E. Roux and A. Borrel, "Journal of "Comparative Pathology and Therapeutics," June 1898, Vol. XI., Part II. 